\title{
Risk management of nutritional supplements in chronic illness: the implications for the care of cancer and depression
}

\author{
Ursula Werneke \\ Department of Psychiatry, Vrinnevi Hospital, 60182 Norrköping, Sweden
}

\begin{abstract}
The use of complementary medicines in patients suffering from chronic illnesses such as cancer and depression is widely documented. Current studies suggest that the prevalence of the use of complementary medicines in patients with cancer ranges from $7 \%$ to $80 \%$. In patients suffering from severe depression the use of complementary medicines may be $>40 \%$. The aim of the present review is to systematically explore the main dimensions that clinicians have to consider when advising patients suffering from these conditions. The Medline and Cochrane databases were searched for evidence relating to the benefits and risks of supplements in the treatment of cancer and depression, including the potential interactions with pharmaco- and radiotherapy. Supplements predominantly used by patients with cancer include vitamins A, C and E, $\beta$-carotene and ubiquinone 10. Supplements predominantly used by patients with depression include S-adenosylmethionine, L-tryptophan and 5-hydroxytryptophan and inositol. Supplements potentially used by both groups include $n-3$ fatty acids, Se and folic acid. Four dimensions are identified and discussed: effectiveness; safety; communication; medico-legal aspects. These dimensions have to be addressed in an illness- and case-specific context. This task can be complex given the emerging clinical evidence, patients' own preferences and expectations and current prescribing guidelines.
\end{abstract}

Nutritional supplements: Risk management: Cancer: Depression

The use of complementary medicines in patients suffering from chronic illnesses is widely documented ${ }^{(1-4)}$. In the present paper the implications of supplement use are explored for cancer and depression. Current studies suggest that the prevalence of the use of complementary medicines in patients with cancer ranges from $7 \%$ to $80 \%{ }^{(2,5)}$. For depression the prevalence may also be high, $>40 \%$ in patients with severe depression ${ }^{(6)}$. Both cancer and depression are conditions that, although fundamentally different, share some common features. They may also coexist. The clinical course can be variable, with complete remission at one end of the spectrum or death at the other. Both conditions are often chronic and may involve a succession of several recurrences and remissions. Patients may not fully recover between episodes and may continue to suffer adverse effects from their treatments. Consequently, it is not surprising that feelings of helplessness and hopelessness are common. Some patients develop 'guilt' feelings, including the feeling of having brought their condition upon themselves or deserving to be punished. Patients may feel that their physical and mental integrity is fundamentally threatened. This state of mind can lead to a sense of powerlessness, loss of control and anxiety ${ }^{(7,8)}$.

Taking complementary alternative medicines and supplements may be, for many patients, a way to regain some control over their illness and ownership of their treatment. Clinicians need to be aware of their patients' motivations and anxieties when discussing the potential benefits and risks of supplements. This task can be complex because the evidence base, albeit expanding, remains limited for many supplements.

The aim of the present review is to systematically review the main dimensions that clinicians must consider when advising patients on supplement use. These dimensions are explored using cancer and depression as examples of common chronic illnesses.

\section{Methods}

Supplements likely to be used in cancer or depression were reviewed with reference to effectiveness and safety. The 
Table 1. Supplements commonly used for cancer prevention and treatment

\begin{tabular}{lcc}
\hline Supplement & Effectiveness based on trial evidence & Potentially-serious side effects \\
\hline Se & Potentially effective for the prevention & Potential slight $\uparrow$ in squamous an \\
of gastrointestinal cancers ${ }^{(73)}$ & non-melanoma skin cancer risk \\
& Clinical trials for prostate cancer & at a dose of $200 \mu$ daily $^{\left({ }^{(1)}\right)}$ \\
& ongoing (SELECT Trial) & \\
& & Acute toxicity: nausea causes \\
& vomiting, nail changes, \\
& irritability and weight loss; \\
& chronic toxicity resembles \\
& As toxicity ${ }^{(82)}$
\end{tabular}

Vitamin A Resolution of oral leukoplakia ${ }^{(74)}$ No effect on the prevention of

Vitamin C

Vitamin $\mathrm{E}$

$\beta$-Carotene

No effect on the incidence of and tract cancers ${ }^{(78)}$

Resolution of oral leukoplakia ${ }^{(74)}$ gastrointestinal cancers ${ }^{(73)}$
Possibly no benefit for prevention and treatment ${ }^{(75)}$

No effect on the prevention of gastrointestinal cancers ${ }^{(73)}$

Potential $\downarrow$ in breast-cancer risk ${ }^{(76)}$ $\uparrow$ Mortality, statistically significant ${ }^{(43)}$

Acute toxicity leads to neuro-psychiatric symptoms including delirium and coma $^{(83)}$ Hepatotoxicity ${ }^{(84,85)}$

Hypervitaminosis leads to skin bone and nail abnormalities ${ }^{(86)}$

Benign intracranial hypertension ${ }^{(87,88)}$

$\downarrow$ Bone density and $\uparrow$ risk of hip fracture with long-term dietary intake $^{(45)}$

Effect on mortality unclear ${ }^{(43)}$

Potential kidney damage through oxalate formation $^{(86)}$

Rebound scurvy after high doses of ingestion ${ }^{(86)}$

\section{$\uparrow$ Mortality $^{(43)}$}

Higher mortality from haemorrhagic stroke in male smokers $^{(14)}$. Risk later confirmed only for hypertensive smokers ${ }^{(60)}$

$\downarrow$ Risk of prostate cancer incidence and mortality in male smokers ${ }^{(77)}$ mortality from upper aerodigestive

No effect on the incidence of and mortality from upper aerodigestive tract cancers, although potential $\downarrow$ in incidence of some laryngeal tumours ${ }^{(78)}$

No effect on the prevention of gastrointestinal cancers ${ }^{(73)}$

Potential $\downarrow$ in breast cancer risk ${ }^{(76)}$

Clinical trials for prostate cancer ongoing (SELECT Trial) ${ }^{(79)}$

$\uparrow$ Mortality $^{(43)}$

$\uparrow$ Mortality from lung cancer and IHD in male smokers ${ }^{(14)}$

$\uparrow$ Incidence of lung cancer, $\uparrow$ mortality from lung cancer and CVD in smokers, ex-smokers and asbestos workers ${ }^{(50)}$

Excess risk not apparent after 4-6 years (non-randomised follow-up) ${ }^{(13)}$
Potentially-significant drug interactions

Chemotherapy

Modification of chemotherapies relying on oxidative stress including taxols, anthracycline antibiotics, 5-fluorouracil, Pt agents, irinotecan ${ }^{(89-91)}$

Unclear whether Se only reduces toxicity and improves therapeutic index of the respective chemotherapies or may affect long-term prognosis by reducing chemotherapy effectiveness ${ }^{(11)}$

May $\uparrow$ cetuximab efficacy in metastatic colorectal cancer ${ }^{(92)}$

Other

Potential $\downarrow$ effect of statins, $\uparrow$ effect of anticoagulants including warfarin ${ }^{(82)}$

May exacerbate hypothyroidism in patients with I-deficient hypothyroidism ${ }^{(93)}$

Other hepatotoxic drugs, including alcohol: $\uparrow$ liver toxicity ${ }^{(85)}$

Retinoids: $\uparrow$ overall toxicity ${ }^{(83)}$

Tetracyclines: $\uparrow$ benign intracranial hypertension ${ }^{(87)}$

Warfarin: $\uparrow$ in bleeding risk through vitamin $\mathrm{K}$ antagonism $^{(83)}$

Chemotherapy

High dose leading to nephrotoxicity through accumulation of methotrexate and precipitating metabolites ${ }^{(46)}$

Other

Statins: $\downarrow$ effectiveness in combination with other oxidants ${ }^{(94)}$

Oestrogen: $\uparrow$ in plasma levels in patients with low baseline concentrations of vitamin $\mathrm{C}^{(94)}$

Chemotherapy

$\downarrow$ in cisplatin-induced neurotoxicity ${ }^{(95)}$

Other

Cyclosporin: water-soluble forms of vitamin $\mathrm{E}$ may $\uparrow$ absorption $^{(96)}$

Statins: $\downarrow$ effectiveness in combination with other oxidants ${ }^{(97)}$

Anticoagulants and anti-platelet drugs: high dose vitamin $\mathrm{E}$ antagonises vitamin K-dependent clotting factors ${ }^{(97)}$

$\uparrow$ Risk of prostate cancer incidence and mortality in male smokers $^{(77)}$ 
Table 1. Continued

\begin{tabular}{cccc}
\hline Supplement & Effectiveness based on trial evidence & Potentially-serious side effects & Potentially-significant drug interactions \\
\hline $\begin{array}{c}\text { Ubiquinone } \\
10\end{array}$ & $\begin{array}{l}\text { Preliminary but inconclusive evidence } \\
\text { of protection against cardiotoxicity } \\
\text { or liver toxicity during cancer } \\
\text { treatment }^{(80)}\end{array}$ & Hypotension & Warfarin: $\downarrow$ efficacy \\
& & & \\
& Antihypertensives: $\uparrow$ effect $^{(99)}$
\end{tabular}

$\uparrow$, Increase; $\downarrow$, decrease.

Medline and Cochrane databases were searched for evidence relating to the benefits and risks of supplements in the treatment of cancer and depression, including the potential interactions with pharmaco- and radiotherapy. Search terms included the identified supplements and vitamins. Additionally, the keywords 'antioxidants', 'CYP', 'toxicity', 'high dose', 'recommended daily intake', 'serotonin', 'serotonin symptom', 'benefit', 'effect', 'effectiveness', 'risk', 'mortality' and 'mechanism of action' were searched. The recovered papers were reviewed for further relevant references. In order to identify potentially-serious side effects and drug interactions web-based resources such as the Natural Medicines Database $2007^{(9)}$ were used. Where available, systematic reviews, meta-analyses and randomised controlled trials were given priority. The results were then interpreted in relation to their potential implications for the clinicianpatient relationship and medico-legal issues.

\section{Results}

Four dimensions are identified and discussed: effectiveness, safety, communication and medico-legal aspects. These dimensions have to be addressed in an illness- and case-specific context.

\section{The effectiveness dimension}

Supplements predominantly used by patients with cancer include $\mathrm{Se}$, vitamins $\mathrm{A}, \mathrm{C}$ and $\mathrm{E}, \beta$-carotene and ubiquinone10. Supplements predominantly used by patients with depression include S-adenosylmethionine (SAMe), Ltryptophan and 5-hydroxytryptophan, folic acid, $n$-3 fatty acids and inositol. The choice of supplements in cancer and depression is mainly but not exclusively guided by identified pathophysiological pathways.

Supplements commonly used for cancer prevention and treatment. Patients with cancer commonly use antioxidants to protect the body against $\mathrm{O}_{2}$-induced tissue damage by handling free radicals and $\mathrm{H}_{2} \mathrm{O}_{2}$. Oxidative stress occurs as part of the normal metabolism, but is also exploited as a chemotherapeutic target in, for example, treatment with anthracycline antibiotics and radiotherapy ${ }^{(10)}$. Oxidative stress may also contribute to undesirable severe side effects such as doxorubicin-induced cardiotoxicity ${ }^{(10,11)}$. The effectiveness of antioxidants may depend on their ability universally to either prevent tissue damage or specifically to repair damage where it has occurred. It seems intuitive to assume that repairing existing tissue damage may be the harder task, requiring higher supplement doses. Also, it may be necessary to match the antioxidant properties to the oxidative mechanism that led to the particular tissue damage originally. The choice of antioxidant as well as the specific formulation of the chosen antioxidant may be important ${ }^{(12)}$. This factor may explain why the effectiveness of most antioxidants in cancer prevention has been rather limited (Table 1). Currently, Se seems to be the most promising supplement, but doubts have been raised about whether the observed anticarcinogenic effects are associated with its pro-oxidant properties rather than its antioxidant properties. Some forms of Se are able to form reactive oxygen species that may induce apoptosis ${ }^{(12)}$. For instance, $\mathrm{Na}_{2} \mathrm{SeO}_{4}$ may be a more potent reactive oxygen species donor than organic forms of Se such as selenomethionine, which seems to be more commonly used. Trials are required to compare the efficacy of both forms ${ }^{(12)}$. The concept that antioxidants can develop pro-oxidant properties under specific conditions may also potentially explain why $\beta$-carotene in combination with smoking may actually increase the mortality from lung cancer ${ }^{(13,14)}$.

Supplements commonly used for depression. Supplements used in the treatment of depression include $n-3$ fatty acids, SAMe, 5-hydroxytryptophan, L-tryptophan, folic acid and Se (Table 2). As with many conventional antidepressants, the objective of using SAMe, 5-hydroxytryptophan, L-tryptophan and folic acid is to increase serotonin availability and/or activity. SAMe, $n-3$ fatty acids and inositol seem to influence cell-membrane composition and second-messenger systems, thereby modifying synaptic neurotransmission.

L-Tryptophan is an essential amino acid that is absorbed from dietary proteins, converted to 5-hydroxytryptophan and then to 5-hydroxytryptamine, i.e. serotonin. In contrast to peripheral serotonin, both L-tryptophan and 5-hydroxytryptophan can cross the blood-brain barrier. However, only $10 \%$ of L-tryptophan is available to the serotonin pathway, whilst the rest is metabolised by an alternative pathway, so that 5-hydroxytryptophan may be more effective at increasing serotonin synthesis ${ }^{(15)}$. Clinical evidence is sparse, presumably because of the continued concerns about an association with eosinophilic myalgic syndrome (see p. 488). The available trial evidence suggests that both L-tryptophan and 5-hydroxytryptophan may be effective antidepressants $^{(16)}$.

SAMe is produced from methionine and ATP. Folic acid is a cofactor in the methylation of homocysteine to methionine ${ }^{(17,18)}$ and may exert its antidepressant action through the increase in SAMe. However, the exact mechanism of the antidepressant action is not clear. SAMe is a methyl donor required for the synthesis of many 
Table 2. Supplements commonly used for the treatment of depression

\begin{tabular}{|c|c|c|c|}
\hline Supplement & Effectiveness based on trial evidence & $\begin{array}{c}\text { Potentially-serious side } \\
\text { effects }\end{array}$ & Significant drug interactions \\
\hline $\begin{array}{l}n-3 \text { Fatty } \\
\text { acids }\end{array}$ & $\begin{array}{l}\text { EPA or a combination of EPA and DHA are } \\
\text { effective as adjunctive treatment. EPA may } \\
\text { have a maximally-effective dose of } 1 \mathrm{mg} / \mathrm{d}^{(25)} \\
\uparrow \text { Remission period when added to } \mathrm{Li} \text { in bipolar } \\
\text { effective disorder }{ }^{(57)}\end{array}$ & $\begin{array}{l}\text { Contamination possible, e.g. } \\
\text { with organic pesticides or } \\
\mathrm{Hg}^{(47,100)}\end{array}$ & Vitamin A: $\uparrow$ risk of toxicity ${ }^{(101)}$ \\
\hline SAMe & $\begin{array}{l}\text { Parenteral SAMe superior to placebo }{ }^{(21)} \\
\text { Comparable efficacy to imipramine in two } \\
\mathrm{RCT}^{(22)} \text {, oral SAMe requires high dose } \\
(1600 \mathrm{mg})^{(22)}\end{array}$ & $\begin{array}{l}\text { Induction of mania in patients } \\
\text { with bipolar affective } \\
\text { disorder }\end{array}$ & $\begin{array}{l}\text { All drugs with direct or indirect } \\
\text { serotonergic effects including } \\
\text { antidepressants and opiates }\end{array}$ \\
\hline $\begin{array}{l}\text { L-Tryptophan, } \\
\text { 5-hydroxy- } \\
\text { tryptophan }\end{array}$ & Preliminary trial evidence of benefit ${ }^{(16)}$ & $\begin{array}{l}\text { Eosinophilic myalgic } \\
\text { syndrome: aetiology and } \\
\text { contaminants remain } \\
\text { unresolved }{ }^{(48)} \\
\text { Theoretically, mania is } \\
\text { possible }\end{array}$ & $\begin{array}{l}\text { All drugs with direct or indirect } \\
\text { serotonergic effects including } \\
\text { antidepressants and opiates }\end{array}$ \\
\hline Folic acid & $\begin{array}{l}\text { Effective as adjunctive treatment and potentially } \\
\text { also as monotherapy. Effect may be dose } \\
\text { dependent }^{(23)}\end{array}$ & $\begin{array}{l}\text { Potential stimulation of bone } \\
\text { marrow }{ }^{(52)} \\
\uparrow \text { Risk of cancer-cell } \\
\text { stimulation in dose higher } \\
\text { than } \operatorname{RDA}^{(53)}\end{array}$ & $\begin{array}{l}\text { Theoretically, partial reversal of anti- } \\
\text { folate therapy, e.g. Methotrexate }{ }^{(56)}\end{array}$ \\
\hline Inositol & $\begin{array}{l}\text { Evidence inconsistent }{ }^{(29)} \text {. No significant effect as } \\
\text { augmentation treatment for treatment resistant } \\
\text { bipolar depression } \\
(31,32)\end{array}$ & $\begin{array}{l}\text { Theoretically, mania is } \\
\text { possible }{ }^{(28)} \\
\text { Fast relapse once treatment }^{(102)} \\
\text { discontinued }^{(12)}\end{array}$ & $\begin{array}{l}\text { None reported } \\
\text { Theoretically may } \downarrow \text { efficacy of } \mathrm{Li} \\
\text { in spite of its own potentially } \\
\text { mood-stabilising and } \\
\text { antidepressant function } \\
{ }^{(27)}\end{array}$ \\
\hline
\end{tabular}

$\uparrow$, Increase; $\downarrow$, decrease; SAMe, S-adenosylmethionine; RCT, randomised controlled trial.

neurotransmitters. SAMe increases serotonin activity in human subjects and has also been shown to increase cerebral concentrations of serotonin and noradrenaline in animal experiments ${ }^{(17)}$. Methylation is also involved in maintaining the integrity of cell membranes, rendering them more fluid. This process may change the configuration of membrane-bound receptors and ion-channels and alter neurotransmission patterns. G protein-receptor coupling-uncoupling dysfunction, which has been implicated in the genesis of mood disorders, may be counter$\operatorname{acted}^{(17,19)}$. Interestingly, stabilisation of neuronal membranes and modulation of second messengers are also purported mechanisms of action for mood stabilisers such as $\mathrm{Li}$ and valproate ${ }^{(20)}$. SAMe has been shown to be superior to placebo and equivalent to tricyclic antidepressants $^{(21,22)}$ and folic acid ${ }^{(23)}$ as an adjunctive treatment for depression.

EPA and DHA are two $n-3$ fatty acids that are integral components of neuronal membranes such as synaptic, dendritic, mitochondrial and vesicle membranes ${ }^{(24)}$. Thus, if there is a lack of these fatty acids the integrity of neuronal membranes and the corresponding neurotransmitter activity may be disturbed. EPA and DHA may have several mechanisms of action operating at different levels. They seem to exert their effectiveness through modification of the cell-membrane structures and influence serotonergic and dopaminergic neurotransmission, regulate corticotrophin-releasing factor and suppress phosphatidylinositol second-messenger activity ${ }^{(25)}$. Additionally, $n-3$ fatty acids have blood-thinning effects that may improve cerebral perfusion ${ }^{(25)}$. Current evidence suggests that EPA alone or in combination with DHA is effective as adjunctive treatment for depressive episodes, in the context of either a unipolar depression or a bipolar disorder ${ }^{(25)}$.

Inositol is yet another substance that has a mechanism of action that is linked to cell-membrane composition. Inositol is a component of cell-membrane phospholipids and a constituent of the intracellular phosphatidylinositol secondmessenger system that is linked to serotonin, noradrenaline and cholinergic receptors ${ }^{(26)}$. Disturbance of this secondmessenger system has been implicated in the genesis of depression $^{(27,28)}$. It has been suggested that decreased phosphoinosite signalling may lead to depression, whereas increased signalling may lead to mania ${ }^{(29)}$. The clinical evidence supporting the use of inositol, however, remains limited $^{(30-32)}$.

Se has also been implicated in the treatment of depression, but no trial has been conducted. Its antioxidant qualities may reduce nerve-cell damage. Additionally, Se is an important cofactor in the conversion of thyroxin to liothyronine. Notably, the brain receives a priority supply in the presence of Se-deprived states ${ }^{(33)}$. In animal experiments increased dopamine and serotonin turnover has been shown to be associated with low Se intake ${ }^{(34)}$. Also, mood states seem to correlate with Se plasma levels ${ }^{(35,36)}$. Whether Se supplementation is an effective treatment of depression remains unclear; a recent trial in healthy volunteers has not found any improvement of $\operatorname{mood}^{(37)}$. 


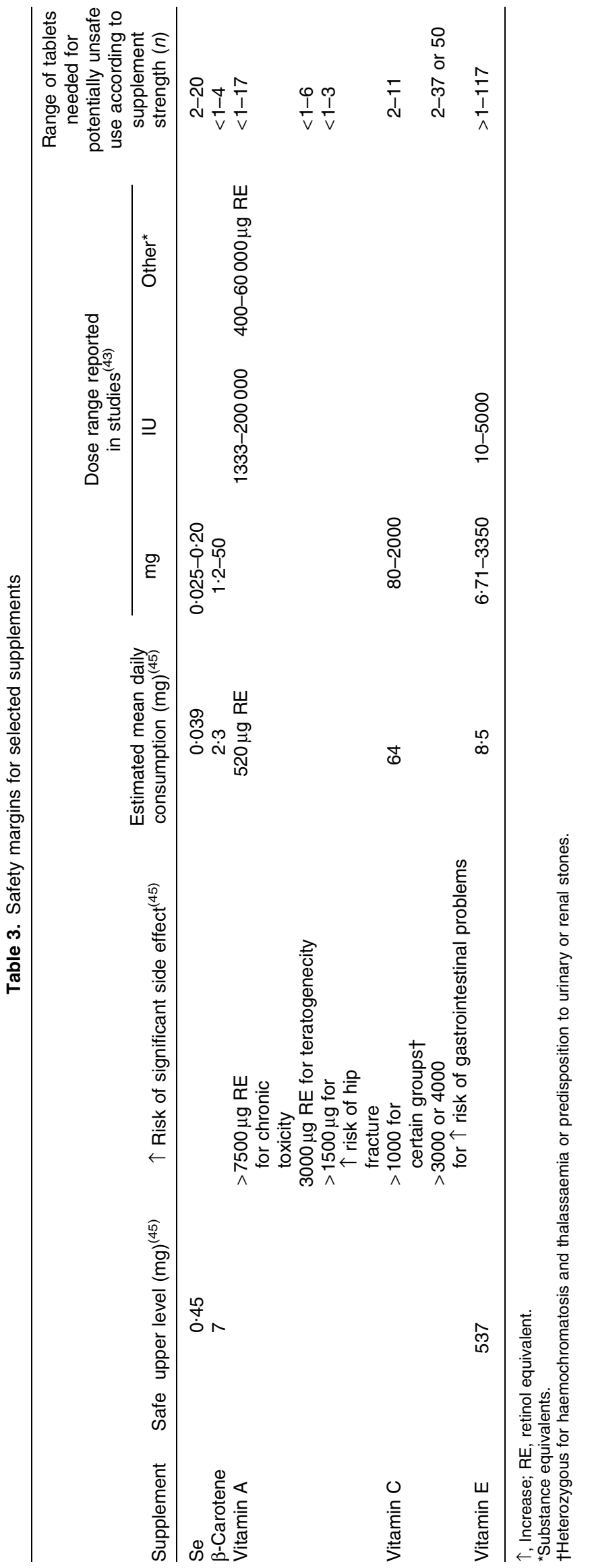

The safety dimension

Taking supplements is not without potential risks. Complementary and alternative medicines have, rightly or wrongly, a very positive 'natural' reputation among substantial sections of the population, and therefore can be popular with patients from a wide variety of cultural backgrounds ${ }^{(4)}$. The potential health risks depend on whether treatments are taken alternatively to or complementary with conventional treatments. If supplements are taken as an alternative treatment there is a risk that patients abandon conventional treatments, potentially to their detriment.

If supplements are taken complementary with conventional treatments health risks may arise from potentiallyserious side effects or drug interaction with conventional medicines. Some health risks may arise from either source. Some of these potential health risks are more tangible than others and therefore may be difficult to quantify. Equally, it can be difficult to predict how research results based on large studies measuring general outcomes such as 'allcause mortality' will impact on individual cases. In particular, the discrepancy between the research findings from large epidemiological studies and randomised controlled trials and meta-analyses needs to be explored further. Although large-cohort studies seem to suggest that antioxidants are generally beneficial ${ }^{(38-42)}$, the outcomes from a recent meta-analysis ${ }^{(43)}$ seem to suggest otherwise. This meta-analysis of sixty-eight randomised controlled trials has found that treatment with $\beta$-carotene, vitamin $\mathrm{A}$ and vitamin $\mathrm{E}$ increases all-cause mortality (Tables 1 and 2).

Some potential health risks can be derived from the purported mechanism of action. Again, it may difficult to predict how such theoretically-derived risks translate into clinical evidence. Obviously, it is unlikely that such risks will be quantified in future, since it would be unethical to initiate studies that purport to explore a potential harmful event as the principal outcome.

Toxic effects. The therapeutic index of a supplement, i.e. the relationship between therapeutic dose and toxic dose, depends on many individual factors, including supplement formulation, water solubility, organ function and other medications taken concomitantly. This margin of safety may be particularly problematic if patients take supplements at higher than the recommended $\operatorname{dose}^{(44)}$. For instance, Se has a narrow therapeutic index. The upper level of safety as recommended by the UK Food Standards Agency $^{(45)}$ is $0.45 \mathrm{mg}$ total Se/d. Se supplements are usually used in strengths between 0.025 and $0.2 \mathrm{mg}$ daily, leaving a narrow margin for patients who chose to take a higher than recommended dose. Calculations can be confusing for those supplements measured in more than one unit, e.g. IU, milligrams or substance equivalents. For some supplements, such as vitamin A, the Food Standards Agency has not issued a safe upper level; thus, defined adverse events such as increased risk of hip fracture and teratogenecity are used as surrogate indicators (Table 3). Usually supplements are offered in various preparations, combinations and in a wide dose range, e.g. for vitamin A from $400 \mu \mathrm{g}$ retinol equivalents to $60000 \mu \mathrm{g}$ retinol equivalents (1333-200000 IU). Furthermore, patients may combine different preparations without realising the 
Table 4. Potential thoughts and associated mood about complementary and conventional medicines

\begin{tabular}{|c|c|c|}
\hline \multirow[b]{2}{*}{ Thought } & \multicolumn{2}{|c|}{ Potential mood } \\
\hline & $\begin{array}{l}\text { Thought accepted } \\
\text { by others }\end{array}$ & $\begin{array}{l}\text { Thought not accepted } \\
\text { by others }\end{array}$ \\
\hline $\begin{array}{l}\text { Complementary medicines are natural and thus harmless. } \\
\text { They have less side effects }\end{array}$ & Safe & Insecure, anxious, suspicious \\
\hline $\begin{array}{l}\text { Complementary medicines are more effective than } \\
\text { conventional therapies }\end{array}$ & Excited & Defensive, ridiculed \\
\hline Conventional therapies have poisoned me & Aggrieved, angry & Angry, deceived \\
\hline Conventional therapies have not worked for me & Disappointed, frustrated & Angry, patronised \\
\hline Complementary medicines boost the effect of my treatment & Hopeful & Rejected, hopeless, helpless \\
\hline Complementary medicines restore my balance with nature & Hopeful, guilty & Hopeless, guilty \\
\hline $\begin{array}{l}\text { Complementary medicines give me control and ownership } \\
\text { of my treatment }\end{array}$ & Assertive & Humiliated, patronised \\
\hline
\end{tabular}

potential of accumulation and associated risks when exceeding safety margins. It may be necessary to highlight to patients how many tablets of a chosen supplement are likely to lead to adverse events (Table 3).

A particular problem arises when high-dose vitamin $\mathrm{C}$ is combined with methotrexate (a chemotherapy drug). This combination may increase methotrexate toxicity and could lead to kidney damage as result of increased plasma methotrexate levels and thus methotrexate toxicity. Vitamin $\mathrm{C}$ acidifies urine and leads to the precipitation of methotrexate and its less-water-soluble metabolites ${ }^{(46)}$.

Contamination. Supplement contamination can also lead to potential health hazards. Fish oil containing n-3 fatty acids and 5-hydroxytryptophan are commonly cited examples. Some cod-liver-oil products have been reported to be contaminated with toxins and pesticides such as polychlorinated biphenyls, hexachlorobenzene, hexachlorocyclohexane isomers and chlorinated pesticides (dichlorodiphenyltrichloroethanes) $^{(47)}$. Even if acceptable safety levels are not exceeded, these substances may accumulate over time. Contamination with heavy metals, in particular $\mathrm{Hg}$, may be a further concern if fish oils are produced from fish caught in contaminated waters. Nevertheless, the overall benefits of $n-3$ fatty acid supplementation are judged to exceed the potential risks ${ }^{(47)}$.

L-Tryptophan and, to a lesser extent, 5-hydroxytryptophan have been associated with eosinophilic myalgic syndrome. In 19891500 cases of L-tryptophanassociated eosinophilic myalgic syndrome were reported, most of which could be traced back to one single manufacturer. The incidence dropped dramatically after L-tryptophan products were limited ${ }^{(48)}$. However, the association has not been fully clarified and five potential contaminants have been identified ${ }^{(49)}$.

Carcinogenesis. The finding that $\beta$-carotene, traditionally used as an antioxidant, was associated with an increased incidence of and mortality from lung cancer in smokers, ex-smokers and asbestos workers ${ }^{(14,50)}$ was unexpected. The mechanism of this adverse effect remains unclear, but may be related to either the pro-oxidative properties of some $\beta$-carotene cleavage products or a direct mutagenic effect ${ }^{(51)}$.

Folic acid is a basic component of cell metabolism and DNA synthesis and repair. Rapidly-dividing cancer cells have an increased requirement for folate to maintain
DNA synthesis ${ }^{(52)}$. Thus, supplementation with folic acid, possibly from a dose of folic acid of $800 \mu \mathrm{g} / \mathrm{d}$, may potentially induce tumour-cell proliferation ${ }^{(53)}$.

Obviously, any supplement contaminated with a carcinogenic substance such as some fertilizers and heavy metals may promote cancer, and patients should be advised to acquire their supplements from a reliable source at all times.

Potential reversal of efficacy of chemotherapies. Chemotherapeutic agents relying on oxidative stress include alkylating agents (e.g. cyclophosphamide, anthracycline) antibiotics (e.g. doxorubicin) and epipodophyllotoxins (e.g. etoposide). Essentially, these agents produce reactive oxygen species to target DNA, thereby arresting cell cycles and inducing apoptosis. Antioxidants may suppress free radical formation and thus compromise the ability of chemotherapeutic agents to destroy micrometastases. This outcome could translate into higher risk of recurrence $^{(10,11)}$. Antioxidants may also promote multi-drug resistance mediated through membrane transporter proteins. Equally, radiotherapy depends on irradiation-induced free radical formation. As a result, antioxidants may at least theoretically compromise radiotherapy results ${ }^{(54,55)}$.

Folic acid, because of its crucial role in DNA metabolism, is an obvious therapeutic target for anti-tumour agents. Theoretically, folic acid supplementation may decrease the efficacy of anti-folate chemotherapies. However, folic acid may also reduce the likelihood of antifolate-associated serious adverse effects ${ }^{(56)}$. As long as the evidence remains conflicting caution is required.

Anticoagulation leading to serious bleeding. n-3 Fatty acids have been shown to inhibit platelet function. Thus, the logical question is whether $n-3$ fatty acids could carry a serious bleeding risk. The available clinical evidence has not upheld such concerns, even for combinations with anticoagulants such as warfarin or aspirin ${ }^{(57,58)}$. Thus, $n-3$ fatty acids are rated as generally safe. Even if the risk is low, however, it does not mean that severe bleeding events can ever be excluded in individual patients. Recently, a case of subdural haematoma in an elderly patient taking high-dose $n-3$ fatty acids in combination with warfarin and aspirin was reported ${ }^{(59)}$.

Vitamin E may antagonise vitamin K-dependent clotting factors, which could translate into an increased risk of haemorrhagic stroke ${ }^{(60)}$. Such an increased risk was reported for male smokers in the original 
Alpha-Tocopherol, Beta-Carotene Prevention Study ${ }^{(14)}$, although subsequently the risk has only been confirmed in the presence of hypertension ${ }^{(60)}$. A 6-year follow-up study has found that the risk of cerebral infarction is increased by $13 \%$, but the investigators suggest that this finding could be a result of chance because no other trial has highlighted an association between vitamin $\mathrm{E}$ and stroke ${ }^{(61)}$.

Serotonin syndrome and induction of mania. Serotonin syndrome is caused by an excess of serotonin in the brain. It is rare but can be potentially life-threatening in its severe form; the extent of severity seems to be dose related. The features of severe serotonin syndrome include autonomic instability, hyperthermia, agitation, hyperreflexia and seizures. Serotonin syndrome can occur when serotonergic drugs or supplements are combined with each other or with substances that facilitate a serotonergic response such as opiates and $\mathrm{Li}^{(62)}$. All serotonergic supplements reviewed here can increase the risk of serotonin syndrome, and a case of serotonin syndrome after the ingestion of tryptophan, St John's wort (Hypericum perforatum) and another unknown substance has been reported ${ }^{(63)}$. All serotonergic supplements may increase the risk of manic episodes in predisposed patients through increased serotonergic neurotransmission, either on their own or more likely in combination with other serotonergic drugs ${ }^{(64-69)}$.

\section{The communication dimension}

In order to understand why patients with cancer and depression may take complementary medicines and specifically supplements it is worthwhile to explore some of the cognitions such patients may experience. As could be expected, the associated mood states can be powerful (Table 4), and it can easily be seen that criticism delivered insensitively can lead to a breakdown of the therapeutic relationship. If the relationship is breaking down, it may be useful to recall this cognitive mindset and the associated emotions. Clinicians must remember that patients make a great emotional investment when trying to take the initiative to re-gain autonomy over a state that may often be perceived as out of control and hopeless. Thus, it is important that patients feel that their views are accepted, even if they cannot be endorsed. At all times it is important to work towards a collaborative relationship.

\section{The medico-legal dimension}

In a time when it has become increasingly difficult to distinguish between defensive medicine and defensible medicine, advising patients on supplement use may cause a dilemma. Clinicians need to be aware of supplementinduced side effects or interactions and should be able to identify hazards, advising patients accordingly and avoiding uncritical encouragement of potentially-harmful use. Ignorance in this area, given the independent usage of complementary and alternative medicines, may lead to criticism and possibly litigation ${ }^{(70)}$. As a starting point, clinicians should always ask about supplement and overthe-counter drug use when taking a history. However, overcautious warnings about the danger of everyday foodstuffs may be equally counter-productive and convey the impression that the clinician is out of touch with reality.
Ultimately, Paracelsus' view that 'all things are poison and nothing is without poison, only the dose permits something not to be poisonous' ${ }^{(71)}$ still holds today.

When discussing supplements clinicians must also consider whether there is a sufficient evidence base for their use at all. Clinicians must further consider which risks would ensue if patients took supplements instead of indicated conventional medicines. This approach is also reflected in UK General Medical Council guidelines on 'Good practice for prescribing medicines'(72). In addition to adhering to all general principles of prescribing the clinician must:

be satisfied that an alternative licensed medicine would not meet the patient's needs;

be satisfied that there is a sufficient evidence base and/ or experience of using the medicine to demonstrate its safety and efficacy;

take responsibility for prescribing the unlicensed medicine and for overseeing the patient's care, including monitoring and any follow up;

record the medicine prescribed and, where the clinician is not following common practice, the reasons for choosing this medicine in the patient's notes.

\section{Conclusions}

Advising patients on the risks and benefits of supplements is a multidimensional task, which must be guided not only by the available clinical and theoretical evidence but also by psychological and medico-legal considerations. For many but not all supplements the clinical evidence for effectiveness and safety remains inconclusive. Nutritional benefits may not translate into benefits from complementary supplement use, and correction of a supplement deficiency may not necessarily lead to the resolution of targeted symptoms. Meta-analyses can be misleading if the studies entered are small and of poor quality and publication bias is not discussed. Equally, it is difficult to monitor the safety of over-the-counter drugs. Ultimately, in many cases patients will have to find their own trade-off between expected benefits and potential risks. Preferences and expectations have to be explored and responded to in the light of the emerging clinical evidence in this area. Decision analyses that formally investigate patients' preferences when trading-off different alternatives are required to gain a deeper understanding of the likely drivers for individual decisions.

\section{References}

1. Eisenberg DM, Kessler RC, Foster C, Norlock FE, Calkins DR \& Delbanco TL (1993) Unconventional medicine in the United States. Prevalence, costs and pattern of use. $N$ Engl J Med 328, 246-252.

2. Ernst E \& Cassileth BR (1999) How useful are unconventional cancer treatments? Eur J Cancer 35, 1608-1613.

3. Werneke U, Ladenheim D \& McCarthy T (2004) Complementary alternative medicine for cancer: a review of effectiveness and safety. Cancer Ther 2B, 475-500. 
4. Werneke U, Turner T \& Priebe S (2006) Complementary alternative medicine in psychiatry: a review of effectiveness and safety. Br J Psych 188, 109-121.

5. Bernstein BJ \& Grasso T (2001) Prevalence of complementary and alternative medicine use in cancer patients. Oncology 15, 1267-1272.

6. Unutzer J, Klap R, Sturm R, Young AS, Marmon T, Shatkin J \& Wells KB (2000) Mental disorders and the use of alternative medicine: results from a national survey. Am J Psychiatry 157, 1851-1857.

7. Moorey S \& Greer S (2002) Cognitive Behaviour Therapy for People with Cancer, 2nd ed., pp. 3-24. Oxford: Oxford University Press.

8. Burns D (1999) Feeling Good, 2nd ed., pp. 19-49. London: Harper Collins Publishers.

9. Therapeutic Research Faculty (2007) Natural medicines comprehensive database. http://www.naturaldatabase.com

10. Labriola D \& Livingston R (1999) Possible interactions between dietary antioxidants and chemotherapy. Oncology 13, 1003-1008.

11. Pommier YG, Goldwasser F \& Strumberg D (2001) Topoisomerase II inhibitors: epipodophyllotoxins, acridines, ellipticines and bisdioxopiperazines. In Cancer Chemotherapy and Biotherapy, 3rd ed., pp. 539-578 [BA Chabner and D Logo, editors]. Philadelphia, PA: Lippincott, Williams \& Wilkins

12. Drake EN (2006) Cancer chemoprevention: selenium as a prooxidant, not an antioxidant. Med Hypotheses 67, 318322.

13. Virtamo J, Pietinen P, Huttunen JK, Korhonen P, Malila N, Virtanen MJ, Albanes D, Taylor PR, Albert P \& ATBC Study Group (2003) Incidence of cancer and mortality following alpha-tocopherol and beta-carotene supplementation: a postintervention follow-up. JAMA 23, 476-485.

14. Alpha-Tocopherol, Beta-Carotene Prevention Study Group (1994) The effect of vitamin $E$ and beta-carotene on the incidence of lung cancer and other cancers in male smokers. $N$ Engl J Med 330, 1029-1035.

15. Turner EH \& Blackwell AD (2005) 5-Hydroxytryptophan plus SSRIs for interferon-induced depression: synergistic mechanisms for normalizing synaptic serotonin. Med $\mathrm{Hy}$ pothesis $\mathbf{6 5}, 138-144$.

16. Shaw K, Turner J \& Del Mar C (2002) Are tryptophan and 5-hydroxytryptophan effective treatments for depression? A meta-analysis. Aust N Z J Psychiatry 36, 488-491.

17. Bottiglieri T (2002) S-Adenosyl-L-methionine (SAMe): from the bench to the bedside - molecular basis of a pleiotrophic molecule. Am J Clin Nutr 76, 1151S-1157S.

18. Morris M, Fava M \& Jaques PF (2003) Depression and folate status in the US population. Psychothep Psychosom 72, 80-87.

19. Schreiber G \& Avissar S (2005) Regulators of G-proteincoupled receptor-G-protein coupling: antidepressants mechanism of action. Expert Rev Neurother 7, 75-84.

20. Hahn CG, Umapathy, Wang HY, Koneru R, Levinson DF \& Friedman E (2005) Lithium and valproic acid treatments reduce PKC activation and receptor-G protein coupling in platelets of bipolar manic patients. J Psychiatr Res 39, 355363.

21. Bressa GM (1994) S-adenosyl-1-methionine (SAMe) as antidepressant: meta-analysis of clinical studies. Acta Neurol Scand 154, Suppl., 7-14.

22. Delle Chiaie R, Pancheri P \& Scapicchio P (2002) Efficacy and tolerability of oral and intramuscular S-adenosylL-methionine 1,4-butanedisulfonate (SAMe) in the treatment of major depression: comparison with imipramine in 2 multicenter studies. Am J Clin Nutr 76, 1172S-1176S.
23. Taylor MJ, Carney S, Geddes J \& Goodwin G (2003) Folate for depressive disorders. Cochrane Database of Systematic Reviews, issue 2, art no. CD003390. Chichester, West Sussex: John Wiley \& Sons Ltd.

24. Hallahan B \& Garland MR (2005) Essential fatty acids and mental health. Br J Psychiatry 186, 275-277.

25. Freeman MP, Hibbeln JR, Wisner KL et al. (2006) Omega-3 fatty acids: evidence basis for treatment and future research in psychiatry. J Clin Psychiatry 67, 1954 1967.

26. Therapeutic Research Faculty (2007) Natural medicines comprehensive database. Key word search 'inositol'. http:॥ www.naturaldatabase.com

27. Dursun SM, Blackburn JR \& Kutcher SP (2001) An exploratory approach to the serotonergic hypothesis of depression: bridging the synaptic gap. Med Hypothesis 56, 235-243.

28. Cheng L, Lumb M, Polgar L \& Mudge AW (2005) How can the mood stabilizer VPA limit both mania and depression? Mol Cell Neurosci 29, 155-161.

29. Taylor MJ, Wilder H, Bhagwagar Z \& Geddes J (2004) Inositol for depressive disorders. Cochrane Database of Systematic Reviews, issue 1, art no. CD004049. Chichester, West Sussex: John Wiley \& Sons Ltd.

30. Levine J (1997) Controlled trials of inositol in psychiatry. Eur Neuropsychopharmacol 7, 147-155.

31. Nierenberg AA, Ostacher MJ, Calabrese JR et al. (2006) Treatment-resistant bipolar depression: a STEP-BD equipoise randomized effectiveness trial of antidepressant augmentation with lamotrigine, inositol, or risperidone. $\mathrm{Am} \mathrm{J}$ Psychiatry 163, 210-216.

32. Eden Evins A, Demopulos C, Yovel I, Culhane M, Ogutha J, Grandin LD, Nierenberg AA \& Sachs GS (2006) Inositol augmentation of lithium or valproate for bipolar depression. Bipolar Disord 8, 168-174.

33. Rayman MP (2000) The importance of selenium to human health. Lancet 356, 233-241.

34. Castano A, Ayala A, Rodriguez-Gomez JA, Herrera AJ, Cano J \& Machado A (1997) Low selenium diet increases the dopamine turnover in prefrontal cortex of the rat. Neurochem Int 30, 549-555.

35. Hawkes WC \& Hornbostel L (1996) Effects of dietary selenium on mood in healthy men living in a metabolic research unit. Biol Psychiatry 39, 121-128.

36. Benton D \& Cook R (1991) The impact of selenium supplementation on mood. Biol Psychiatry 29, 1092-1098.

37. Rayman M, Thompson A, Warren-Perry M, Galassini R, Catterick J, Hall E, Lawrence D \& Bliss J (2006) Impact of selenium on mood and quality of life: a randomized, controlled trial. Biol Psychiatry 59, 147-154.

38. Hayden KM, Welsh-Bohmer KA, Wengreen HJ, Zandi P, Lyketsos C \& Breitner J (2007) Risk of mortality with vitamin E supplements: the Cache County study. Am J Med 120, 180-184.

39. Wright ME, Lawson KA, Weinstein SJ, Pietinen P, Taylor PR, Virtamo J \& Albanes D (2006) Higher baseline serum concentrations of vitamin $\mathrm{E}$ are associated with lower total and cause-specific mortality in the Alpha-Tocopherol, BetaCarotene Cancer Prevention Study. Am J Clin Nutr 84, 959960.

40. Jacobs EJ, Henion AK, Briggs PJ, Connell CJ, McCullough ML, Jonas CR, Rodriguez C, Calle EE \& Thun MJ (2002) Vitamin $\mathrm{C}$ and vitamin $\mathrm{E}$ supplement use and bladder cancer mortality in a large cohort of US men and women. Am J Epidemiol 156, 1002-1010.

41. Dagnelie PC, Schuurman AG, Goldbohm RA \& Van den Brandt PA (2004) Diet, anthropometric measures and 
prostate cancer risk: a review of prospective cohort and intervention studies. BJU Int 93, 1139-1150.

42. Longnecker MP, Martin-Moreno JM, Knekt P, Nomura AM, Schober SE, Stahelin HB, Wald NJ, Gey KF \& Willett WC (1992) Serum alpha-tocopherol concentration in relation to subsequent colorectal cancer: pooled data from five cohorts. J Natl Cancer Inst 84, 430-435.

43. Bjelakovic G, Nikolova D, Gluud LL, Simonetti RG \& Gluud C (2007) Mortality in randomized trials of antioxidant supplements for primary and secondary prevention: systematic review and meta-analysis. JAMA 297, 842-857.

44. Werneke U, Earl J, Seydel C, Horn O, Crichton P \& Fannon D (2004) Potential health risks of complementary alternative medicines in cancer patients. $\mathrm{Br} J$ Cancer $\mathbf{9 0}$, 408-413.

45. Expert Group on Vitamins and Minerals (2003) Safe upper levels for vitamins and minerals. http://www.food.gov.uk/ multimedia/pdfs/vitmin2003.pdf

46. Sketris IS, Farmer PS \& Fraser A (1984) Effect of vitamin $\mathrm{C}$ on the excretion of methotrexate. Cancer Treat Rep $\mathbf{6 8}$, 446-447.

47. Bays HE (2006) Safety considerations with omega-3 fatty acid therapy. Am J Cardiol 99, 35C-43C.

48. Therapeutic Research Faculty (2007) Natural medicines comprehensive database. Key word search 'L-tryptophan, 5-hydroxytryptophan'. http://www.naturaldatabase.com

49. Simat TJ, Kleeberg KK, Muller B \& Sierts A (1999) Synthesis, formation, and occurrence of contaminants in biotechnologically manufactured L-tryptophan. Adv Exp Med Biol 467, 469-480.

50. Omenn GS, Goodman GE, Thornquist MD et al. (1996) Effects of a combination of beta carotene and vitamin A on lung cancer and cardiovascular disease. N Engl J Med 334, 1150-1155.

51. Alija AJ, Bresgen N, Sommerburg O, Siems W \& Eckl PM (2004) Cytotoxic and genotoxic effects of beta-carotene breakdown products on primary rat hepatocytes. Carcinogenesis 25, 827-831.

52. Kelemen LE (2006) The role of folate receptor alpha in cancer development, progression and treatment: cause, consequence or innocent bystander? Int J Cancer 119, 243250.

53. Therapeutic Research Faculty (2007) Natural medicines comprehensive database. Key word search 'folic acid'. http://www.naturaldatabase.com

54. Agostinelli E \& Seiler N (2006) Non-irradiation-derived reactive oxygen species (ROS) and cancer: therapeutic implications. Amino Acids 31, 341-345.

55. D'Andrea GM (2005) Use of antioxidants during chemotherapy and radiotherapy should be avoided. CA Cancer $J$ Clin 55, 319-321.

56. Calvert H (2002) Folate status and the safety profile of antifolates. Semin Oncol 2, Suppl. 5, 3-7.

57. Stoll AL, Severus WE, Freeman MP, Rueter S, Zboyan HA, Diamond E, Cress KK \& Marangell LB (1999) Omega 3 fatty acids in bipolar disorder: a preliminary doubleblind, placebo-controlled trial. Arch Gen Psychiatry 56, 407-412.

58. Harris WS (2007) Expert opinion: omega-3 fatty acids and bleeding - cause for concern? Am J Cardiol 99, 44C46C.

59. McClaskey EM \& Michalets E (2007) Subdural hematoma after a fall in an elderly patient taking high-dose omega-3 fatty acids with warfarin and aspirin: case report and review of the literature. Pharmacotherapy 27, 152-160.

60. Booth SL, Golly I, Sacheck JM, Roubenoff R, Dallal GE, Hamada K \& Blumberg JB (2004) Effect of vitamin E supplementation on vitamin $\mathrm{K}$ status in adults with normal coagulation status. Am J Clin Nutr 80, 143-148.

61. Tornwall ME, Virtamo J, Korhonen PA, Virtanen MJ, Albanes D \& Huttunen JK (2004) Postintervention effect of alpha tocopherol and beta carotene on different strokes: a 6year follow-up of the Alpha Tocopherol, Beta Carotene Cancer Prevention Study. Stroke 35, 1908-1913.

62. Nieuwstraten C, Labiris NR \& Holbrook A (2006) Systematic overview of drug interactions with antidepressant medications. Can J Psychiatry 51, 300-316.

63. Bryant SM \& Kolodchak J (2004) Serotonin syndrome resulting from a herbal detox cocktail. Am J Emerg Med 22, 625-626.

64. Friedel HA, Goa KL \& Benfield P (1989) S-adenosylL-methionine. A review of its pharmacological properties and therapeutic potential in liver dysfunction and affective disorders in relation to its physiological role in cell metabolism. Drugs 38, 389-416.

65. Mischoulon D \& Fava M (2002) Role of S-adenosylL-methionine in the treatment of depression: a review of the evidence. Am J Clin Nutr 76, 1158S-1161S.

66. Jones D \& Story DA (2005) Serotonin syndrome and the anaesthetist. Anaesth Intensive Care 33, 181-187.

67. Pariante CM, Orru MG, Carpiniello B \& Rudas N (1995) Multiple sclerosis and major depression resistant to treatment. Case of a patient with antidepressive therapy-induced mood disorder, associated with manic features. Clin Ther 146, 449-452.

68. Patterson BD \& Srisopark MM (1989) Severe anorexia and possible psychosis or hypomania after trazodone-tryptophan treatment of aggression. Lancet i, 1017.

69. Goff DC (1985) Two cases of hypomania following the addition of L-tryptophan to a monoamine oxidase inhibitor. Am J Psychiatry 142, 1487-1488.

70. Cohen MH \& Eisenberg DM (2002) Potential physician malpractice liability associated with complementary and integrative medicinal therapies. Ann Intern Med 136, 596603.

71. Wikipedia (2007) Paracelsus. http://en.wikipedia.org/wiki/ Paracelsus

72. General Medical Council (2006) Good practice for prescribing medicines. http://www.gmc-uk.org/guidance/ current/library/prescriptions (accessed May 2006).

73. Bjelakovic G, Nikolova D, Simonetti RG \& Gluud C (2004) Antioxidant supplements for prevention of gastrointestinal cancers: a systematic review and meta-analysis. Lancet 364, 1219-1228.

74. Lodi G, Sardella A, Bez C, Demarosi F \& Carrassi A (2006) Interventions for treating oral leukoplakia. Cochrane Database of Systematic Reviews, issue 4, art. no. CD001829. Chichester, West Sussex: John Wiley \& Sons Ltd.

75. Coulter ID, Hardy ML, Morton SC, Hilton LG, Tu W, Valentine D \& Shekelle PG (2006) Antioxidants vitamin C and vitamin $\mathrm{E}$ for the prevention and treatment of cancer. $J$ Gen Intern Med 21, 735-744.

76. Gandini S, Merzenich H, Robertson C \& Boyle P (2000) Meta-analysis of studies on breast cancer risk and diet: the role of fruit and vegetable consumption and the intake of associated micronutrients. Eur J Cancer 36, 636646.

77. Heinonen OP, Albanes D, Virtamo J et al. (1998) Prostate cancer and supplementation with alpha-tocopherol and beta-carotene: incidence and mortality in a controlled trial. $J$ Natl Cancer Inst 90, 440-446.

78. Wright ME, Virtamo J, Hartman AM, Pietinen P, Edwards BK, Taylor PR, Huttunen JK \& Albanes D 
(2007) Effects of alpha-tocopherol and beta-carotene supplementation on upper aerodigestive tract cancers in a large, randomized controlled trial. Cancer 109, 891-898.

79. Etminan M, FitzGerald JM, Gleave M \& Chambers K (2005) Intake of selenium in the prevention of prostate cancer: a systematic review and meta-analysis. Cancer Causes Control 16, 1125-1131.

80. Roffe L, Schmidt K \& Ernst E (2004) Efficacy of coenzyme Q10 for improved tolerability of cancer treatments: a systematic review. J Clin Oncol 22, 4418-4424.

81. Duffield-Lillico AJ, Slate EH, Reid ME et al. (2003) Selenium supplementation and secondary prevention of nonmelanoma skin cancer in a randomized trial. J Natl Cancer Inst 95, 1477-1481.

82. Therapeutic Research Faculty (2007) Natural Medicines Comprehensive Database. Key word search 'selenium'. http://www.naturaldatabase.com

83. Therapeutic Research Faculty (2007) Natural medicines comprehensive database. Key word search 'vitamin A'. http://www.naturaldatabase.com

84. Nollevaux MC, Guiot Y, Horsmans Y, Leclercq I, Rahier J, Geubel AP \& Sempoux C (2006) Hypervitaminosis A-induced liver fibrosis: stellate cell activation and daily dose consumption. Liver Int 26, 182-186.

85. Maddrey WC (2005) Drug-induced hepatotoxicity. J Clin Gastroenterol 39, Suppl. 2, S83-S89.

86. Page C, Curtis M, Walker M \& Hoffman B (2006) Integrated Pharmacology, 2nd ed., pp. 589-608. Oxford: Mosby Elsevier.

87. Friedman DI (2005) Medication-induced intracranial hypertension in dermatology. Am J Clin Dermatol 6, 29-37.

88. Fraunfelder FW \& Fraunfelder FT (2004) Evidence for a probable causal relationship between tretinoin, acitretin, and etretinate and intracranial hypertension. J Neuroophthalmol 24, 214-216.

89. Danesi F, Malaguti M, Nunzio MD, Maranesi M, Biagi PL $\&$ Bordoni A (2006) Counteraction of adriamycin-induced oxidative damage in rat heart by selenium dietary supplementation. J Agric Food Chem 22, 1203-1208.

90. Fakih M, Cao S, Durrani FA \& Rustum YM (2005) Selenium protects against toxicity induced by anticancer drugs and augments antitumor activity: a highly selective, new, and novel approach for the treatment of solid tumors. Clin Colorectal Cancer 5, 132-135.
91. Azrak RG, Cao S, Pendyala L, Durrani F, Fakih M, Combs G, Prey J, Smith P \& Rustum Y (2007) Efficacy of increasing the therapeutic index of irinotecan, plasma and tissue selenium concentrations is methylselenocysteine dose dependent. Biochem Pharmacol 73, 1280-1287.

92. Altundag K, Silay YS, Altundag O, Yigitbasi OG, Gundeslioglu O \& Gunduz M (2005) Selenium supplementation may increase the efficacy of cetuximab in metastatic colorectal cancer patients. Med Hypotheses 64, 11621165 .

93. Kohrle J (2005) Selenium and the control of thyroid hormone metabolism. Thyroid 15, 841-853.

94. Therapeutic Research Faculty (2007) Natural medicines comprehensive database. Key word search 'vitamin C'. http:// www.naturaldatabase.com

95. Pace A, Savarese A, Picardo M et al. (2003) Neuroprotective effect of vitamin $\mathrm{E}$ supplementation in patients treated with cisplatin chemotherapy. J Clin Oncol 21, 927931.

96. Sokol RJ, Johnson KE, Karrer FM, Narkewicz MR, Smith D \& Kam I (1991) Improvement of cyclosporin absorption in children after liver transplantation by means of watersoluble vitamin E. Lancet 338, 212-214.

97. Therapeutic Research Faculty (2007) Natural medicines comprehensive database. Key word search 'vitamin E'. http://www.naturaldatabase.com

98. Therapeutic Research Faculty (2007) Natural medicines comprehensive database. Key word search 'beta-carotene'. http://www.naturaldatabase.com

99. Therapeutic Research Faculty (2007) Natural medicines comprehensive database. Key word search 'co-enzyme Q10'. http://www.naturaldatabase.com

100. Storelli MM, Storelli A \& Marcotrigiano GO (2004) Polychlorinated biphenyls, hexachlorobenzene, hexachlorocyclohexane isomers, and pesticide organochlorine residues in cod-liver oil dietary supplements. J Food Prot 67, 1787-1791.

101. Koller H, Luley C, Klein B, Baum H \& Biesalski HK (1989) Contaminating substances in 22 over-the-counter fish oil and cod liver oil preparations: cholesterol, heavy metals and vitamin A. Z Ernahrungswiss 28, 76-83.

102. Levine J, Barak Y, Kofman O \& Belmaker RH (1995) Follow-up and relapse analysis of an inositol study of depression. Isr J Psychiatry Relat Sci 32, 14-21. 